\title{
Resenfia
}

\section{INTERNATIONAL HANDBOOK OF PROFESSIONAL IDENTITITES}

\author{
Manual Internacional sobre Identidades Profissionais
}

\author{
Ana Maria Costa e Silva ${ }^{1}$ \\ Miriam T. Aparicio ${ }^{2}$
}

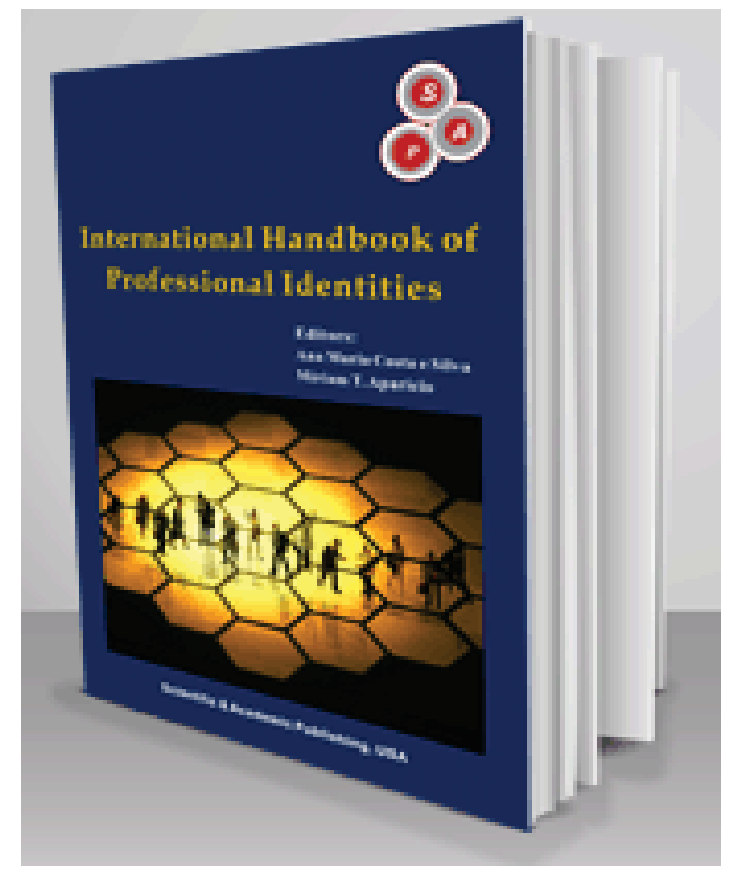

Editoras: Ana Maria Costa e Silva \& Miriam T.

Aparício

Primeira edição original em inglês: abril de 2015

Título: International Handbook of Professional Identities.

Editora: Scientific \& Academic Publishing

Lugar de edição: USA.

Número de páginas: 341

Ano: 2015

ISBN: 978-1-938681-35-6

Este livro coletivo, publicado recentemente nos Estados Unidos da América, foi organizado pelas editoras Ana Maria Costa e Silva e Miriam Aparicio. Ambas as autoras se dedicam, há mais de uma década, à pesquisa e docência no âmbito das identidades profissionais reconhecendo que os estudos sobre as profissões, as suas evoluções e (re)configurações são fundamentais para uma consistente formação

\footnotetext{
${ }^{1}$ Professora Titular de graduação e pós-graduação e investigadora integrada do Centro de Estudos em Comunicação e Sociedade, na Universidade do Minho, Campus de Gualtar, Braga, Portugal. Telefone +351253604608. E-mail: anasilva@ie.uminho.pt.

2 Investigadora principal do CONICET e professora titular de graduação e pós-graduação na Universidade Nacional de Cuyo, Mendonza, Argentina. E-mail: miriamapar@yahoo.com.
} 
académica dos estudantes e profissionais e para a configuração de planos de estudos adequados às novas realidades sociais e profissionais. Também os vinte autores de vários continentes, que participam no livro, têm pesquisas relevantes neste domínio.

O estudo sobre as profissões e as identidades profissionais não é recente. Há mais de um século que o interesse pela definição e caracterização do significado de profissão tem estado presente nas obras de vários sociólogos. O reconhecimento de Durkheim (1893) de que "um dia virá, onde a nossa organização social e política terá uma base exclusivamente ou quase exclusivamente profissional” está na origem do debate sobre o que caracteriza e pode ser denominado como profissão.

Ao longo de grande parte do século XX surgiram estudos e abordagens diferentes, nomeadamente no âmbito da sociologia das profissões, da psicologia das organizações, da ergonomia, da educação. O interesse que tem sido dado ao debate em torno das profissões e dos grupos profissionais deve ser percebido no quadro da relevância que o trabalho e o emprego têm assumido, quer do ponto de vista social e económico, quer do ponto de vista individual e da identidade pessoal e social. Neste debate estão presentes as questões relativas à autonomia, à legitimidade e ao reconhecimento, elementos importantes na apresentação do eu no palco da vida quotidiana (GOFFMAN, 2000), na construção e reconstrução da identidade e nas dinâmicas identitárias dos indivíduos e dos grupos em que se integram.

A relação entre trabalho, profissão e identidade ganha particular visibilidade a partir do último quarto do século XX, sendo a obra de René Sainsaulieu nos anos 80, nomeadamente o livro 'Identité au Travail', uma referência importante dessa visibilidade, continuada e aprofundada por outros estudiosos, entre os quais Claude Dubar, Denis Segrestin, Hermínia Ibarra, Michael Pratt.

As políticas de trabalho e de formação, as reformas na administração pública que se vêm produzindo e multiplicando por todo o mundo e o seu impacto nos indivíduos e nos grupos profissionais, mantêm atual o interesse e o debate acerca das identidades profissionais, introduzindo novas dimensões de análise e a necessidade do seu aprofundamento. Salientam-se as políticas públicas inspiradas na doutrina do denominado New Public Management (NPM) e as suas repercussões nos grupos profissionais, nomeadamente na sua autonomia (BEZES et al., 2011), as relações entre a oferta de formação e de emprego, as dinâmicas sociais e as exigências de novas 
respostas profissionais que se refletem na expressão, na visibilidade e no reconhecimento dos grupos profissionais, assim como na sua recomposição.

Considerando a relevância deste tema, o objetivo deste livro é proporcionar aos leitores um questionamento sobre as mudanças socio-económicas e políticas com impacto no mundo do trabalho e das carreiras profissionais. A situação atual relativa ao trabalho e ao emprego, a sua precarização e reorganização reflete-se nas pessoas, a nível socioprofissional e individual, nas suas experiências e identidades, incluindo as identidades profissionais.

Estamos, assim, perante um cenário que nos trás novas questões e desafios, pelo que os contributos mais recentes neste domínio teóricos e disciplinares são muito importantes. Neste sentido, este livro proporciona leituras relevantes sobre este tema a partir de pesquisas internacionais e multidisciplinares. Salientamos a diversidade de contributos, que oferecem perspetivas diversas e enriquecedoras do campo em análise: as identidades profissionais. Na organização deste livro tivemos presente a necessidade de alargar o debate e promover o diálogo a contextos geográficos, científicos e profissionais diferenciados e também menos representados na literatura existente sobre esta temática trazendo a palco a transversalidade e atualidade desta discussão no âmago da globalização.

Importa registar que, apesar da diversidade de perspetivas e de análises, assim como dos objetos em discussão, são frequentemente mobilizadas pelos autores dos diversos capítulos referências clássicas no âmbito das discussões sobre as profissões e as identidades dos grupos profissionais. A título de exemplo, Abbott, Becker, Dubar, Gergen, Hughes, Larson, Sainsaulieu são autores referidos, reconhecendo-se, assim, o seu contributo para a continuidade e aprofundamento dos estudos neste âmbito.

O livro está organizado em três partes, cada uma delas focada em aspetos centrais acerca desta temática.

Na Parte I, cinco capítulos trazem leituras e propostas sobre o Panorama e contributos de diferentes disciplinas e teorias para as identidades profissionais. Os textos, para além de se inscreverem em diferentes perspetivas de análise, predominantemente teóricas, oferecem propostas desde diversas áreas disciplinares e lugares geográficos e institucionais, enriquecendo a leitura, análise e o debate em torno da temática e da sua atualidade, contando com autores de referência como: Michael G. Pratt, Douglas Lepisto \& Eliana Crosina (EUA), Bader Burihan Sawaya (Brasil), AnneServ. Soc. \& Saúde, Campinas, SP v.14, n. 2 (20), p. 279-282, jul./dez. 2015 ISSN 1676-6806 
Marie Costalat-Founeau (França), Telmo Caria \& Marise Ramos (Portugal e Brasil), Maria Lúcia Martinelli (Brasil).

A Parte II incide nos Lugares de construção de identidades profissionais, nomeadamente os contextos de trabalho, de formação - inicial e contínua - a carreira e as expectativas profissionais. Os diversos capítulos que integram esta parte do Handbook, referem-se a estudos empíricos, alguns deles longitudinais, e a análises teóricas e são da autoria de Rémi Kouabenan \& Robert Ngueutsa (França), Miriam T. Aparicio (Argentina), Ana Paula Marques (Portugal), Daniel Quilaqueo, Segundo E. Quintriqueo \& Enrique H. Riquelme (Chile), Ana Maria Costa e Silva (Portugal).

A Parte III foca-se nos Grupos profissionais e suas identidades, enriquecendo a leitura e o debate clássico e atual entre profissões, semi-profissões e grupos profissionais e, sobretudo, acerca dos desafios com que se confrontam na atualidade, como é o caso dos professores (Amélia Lopes, Portugal), dos advogados (Ma. Francisca Pajarito \& María Luisa Chavoya Peña, México), dos mediadores (Florencia Brandoni, Argentina), e dos assistentes sociais (Raquel Raichelis, Edna Goulart Joazeiro, Brasil).

Este livro congrega um conjunto de textos focados nas identidades profissionais e nos aspetos que lhe estão subjacentes na atualidade, sejam de natureza teóricaconcetual, política, socioeconómica ou psicossocial. Proporciona, por isso, um marco de problematização e reflexão sobre a realidade e os desafios que se colocam à continuidade dos estudos nesta área.

Recebida em 07.12.2015 - Aprovada em 15.12.2015

\section{REFERENCIAS}

BEZES, P. ; DEMAZIERE, D. ; LE BIANC, T. ; PARADEISE, C. ; NORMANDE, R. et al. New Public Management et professions dans l'État: au-delá des oppositions, quelles recompositions, Sociologie du Travail, 53, 2011, p. 293-348.

DURKHEIM, E. A Divisão do Trabalho Social. Lisboa: Editorial Presença, 1984. (First edition 1893).

GOFFMAN, E. La mise en scène de la vie quotidienne. Paris: Les Editions de Minuit, 2000.

SAINSAULIEU, R. L’identité au travail. Paris : Presses de la Fondation Nationale des Sciences Politiques, 1988. 